\title{
ANALISIS STUDI KELAYAKAN PEMBENTUKAN LEMBAGA PENERBIT (UMT PRESS) UNIVERSITAS MUHAMMADIYAH TANGERANG
}

\author{
Desri Arwen ${ }^{1}$, Zalzulifa ${ }^{2}$, Nasaruddin ${ }^{3}$, Sukwan Hanafi ${ }^{4}$ \\ Email : ${ }^{1)}$ desriarwen72@gmail.com, ${ }^{2}$ zalzulifa@gmail.com, ${ }^{3)}$ nasarbima.nb@gmail.com, \\ ${ }^{4)}$ hanafisukwan@gmail.com \\ 1) Universitas Muhammadiyah Tangerang, ${ }^{2)}$ Politeknik Negeri Media Kreatif ${ }^{3)}$ Sekolah Tinggi \\ Keguruan Dan Ilmu Pendidikan (STKIP) Pancakarya Tangerang, ${ }^{4)}$ Afiliasi Penerbit Perguruan \\ Tinggi Muhammadiyah Aisyiah (APPTIMA)
}

\begin{abstract}
Abstrak
Tujuan penelitian yaitu untuk menganalisis kelayakan faktor pendukung dalam pembentukan lembaga penerbit (UMT Press). Jenis penelitian yang digunakan yaitu survey dengan metode kuantitatif. Sampel pada penelitian ini diperoleh dari 26 orang dosen yang diambil dengan menggunakan pendekatan purposive sampling atau pengambilan sampel secara sengaja yang mewakili 8 program studi, mereka dianggap memiliki pengetahuan lebih tentang masalah yang ditelitiUntuk metode analisis yang digunakan pada penelitian ini yaitu analisis statistik deskriptif dan analisis SWOT. Instrument pengumpulan data dengan angket tertutup dan terbuka. Hasil analisis SWOT diperoleh pada faktor internal meliputi aspek kekuatan dan kesempatan dalam pembentukan lembaga penerbit (UMT Press) dalam kategori kuat dan aspek kelemahan dan ancaman (faktor internal) dapat diminimalisir dengan gabungan aspek kekuatan dan kesempatan.
\end{abstract}

Kata Kunci: SWOT, Faktor Internal, Faktor Eksternal, Lembaga Penerbit.

\begin{abstract}
The research objective is to analyze the feasibility of supporting factors in forming a publishing agency (UMT Press). This type of research is a survey with quantitative methods. The sample in this study was obtained from 26 lecturers using a purposive sampling approach representing 8 study programs. The Data collected with a closed and open questionnaire. SWOT analysis results obtained on internal factors include aspects of strengths and opportunities in the formation of a publishing agency (UMT Press) in the sharp category. The study reveals that weaknesses and threats issues can be minimized with the combination of strengths and opportunities.
\end{abstract}

Keywords: SWOT, Internal Factors, External Factors, Issuing Institutions.

\section{PENDAHULUAN}

Hakikat keberadaan lembaga penerbit di lingkungan perguruan tinggi adalah dapat membawa nilai kemanfaatan bagi anggota secara internal dan eksternal. Kegiatan awal dalam pembentukan lembaga lembaga penerbit di lingkungan perguruan tinggi adalah proses perencanaan yang matang. Perencanaan yang baik adalah suatu perencanaan yang menganalisis secara menyeluruh dalam menilai kelayakan semua komponenkomponen pendukung lembaga tersebut. Selain dari perencanaan yang matang, perlu didukung oleh komponen pendukung lain seperti sumber daya manusia dalam hal ini Dosen, mesin cetak, dana, kebijakan pimpinan dan manajemen secara professional. Dalam lingkungan Universitas Muhammadiyah Tangerang (UMT) yang berhubungan dengan komponen pendukung lembaga penerbit mengalami permasalahan serius sebagaimana hasil temuan pada studi pendahulu tanggal 20 Februari 2020 ditemuakan beberapa permasalahan seperti; 1) Keterbatasan dana. Dalam dunia penerbitan, uang menjadi hal yang sangat penting. Mati hidupnya sebuah penerbitan buku, baik kampus maupun non kampus, sangat bergantung dengan dukungan dana. Menjamurnya penerbitan buku yang muncul pasca reformasi, tetapi tidak sedikit dari penerbit-penerbit itu tidak mampu beroperasi karena persoalan uang. Tak jarang penerbit-penerbit swasta, khususnya buku mencari pinjaman ke bank, dan setiap bulan harus mencicilnya. Dan tak jarang pula, akhirnya gulung tikar; 2) Rendahnya budaya tulis menulis. Menumbuhkan budaya tulis menulis tidak gampang dilakukan. Karena, aktifitas menulis menuntut seseorang untuk dapat sedikit meluangkan waktu dan cukup menyita pikiran. Mungkin alasan inilah yang mendorong seorang pengajar (dosen) untuk lebih suka 
menyampaikan materi ajar secara lisan atau ceramah; 3) Kualitas buku yang rendah. Faktor ini seringkali dihubungkan dengan ketidak-seriusan penulis yang bersangkutan. Ini terkait dengan rendahnya budaya tulis menulis yang dimiliki oleh seseorang. Pada umumnya, seseorang lebih mempertimbangkan besar-kecilnya honor yang diterima katimbang berkarya (menulis) itu sendiri, sehingga mereka lebih suka memilih jalan pintas dalam berkarya. Selain minim perhatian otoritas, penerbit perguruan tinggi juga mengeluhkan minimnya minat dosen untuk menulis buku.

Permasalahan di atas merupakan suatu gejala yang tampak dan tidak pernah terlepas dari hal-hal yang paling fundamental yang menyebabkan gejala itu muncul. Oleh karena itu sangat diperlukan kajian secara mendalam agar detemukan faktor-faktor yang paling dominan sebagai pendukung dan penghambat pendirian lembaga penerbit (UMT Press). Dengan adanya studi kelayakan seperti ini, manajemen lembaga penerbit nanti setidaknya memiliki arahan untuk perbaikan atau pengembangan baik yang berkaitan dengan faktor internal maupun faktor eksternal. Oleh sebab itu peneliti tertatik untuk meneliti dengan judul "Analisis Studi Kelayakan Pembentukan Lembaga Penerbit (UMT Press) Universitas Muhammadiyah Tangerang" Berdasarkan judul penelitian di atas, maka yang menjadi fokus penelitian adalah layak atau tidak layak faktor internal yang mendukung pembentukan lembaga penerbit (UMT Press) yaitu faktor kekuatan (strength) dan mampu mengambil keuntungan dari kesempatan (opportunity) dan kekuatan tersebut mampu menghadap ancaman dan mengatasi kelemahan. Faktor internal yang dimaksud adalah aspek sumber daya manusia (SDM) yang mencakup; pengalaman mengajar dan menulis dan, beberapa hambatan dalam penulisan Dosen.

Berdasarkan fokus kajian di atas, maka pertanyaan penelitian secara yaitu pertama, sejauhmana faktor kekuatan (strength) pembentukan lembaga penerbit (UMT Press) mampu mengambil keuntungan dari kesempatan (opportunity)?, kedua, sejauhmana faktor kekuatan (strength) pembentukan lembaga penerbit (UMT Press) mampu menghadap ancaman? Dan yang ketiga sejauhmana faktor kekuatan (strength) pembentukan lembaga penerbit (UMT Press) mampu mengatasi kelemahan?

Beradasarkan fokus dan pertanyaan penelitian di atas, maka teori dasar (grand theory) sebagai pijakan dalam penelitian adalah teori manajemen strategis. Teori manajemen strategis yaitu untuk menjelaskan tindakan-tingakan alternative suatu organisasi untuk mencapai tujuan yang telah ditentukan sebelumnya baik yang berkaitan dengan tujuan jangka pendek, jangka menengah maupun jangka panjang. Dengan adanya strategi yang tepat, maka lembaga penerbit tersebut akan melakukan perencanaan yang matang, mengalokasikan sumber daya yang dimilikinya agar tetapa berjalan dan mendapatkan keunggulan kompetitif.
Dalam manajemen strategis, sumber yang dimiliki organisasi adalah dasar pendorong bagi oraganiasi itu sendiri dalam mencapai keunggulan kompetitif. Selain dari sumber daya manusia, Sumber daya lain mencakup semua aset, kemampuan manajemen, proses organisasi, atribut perusahaan, informasi, pengetahuan, dll (Hashim, 2000). Dalam rumusan strategis suatu organisasi harus melalui langkah-langkah strategi terutama yang mencakup: a) Misi organisasi atau tujuan jangka panjang b) kekuatan, kesempatan, anacaman dan kelemahan bagi perusahaan (SWOT) (Omalaja, Eruola, \& College, 2011). Analisis SWOT bertujuan untuk membantu organisasi untuk mendapatkan pemahaman yang lebih baik tentang kondisi lingkungan baik secara internal maupun secara eksternal ketika lembaga (organisasi) dalam menentukan keputusan strategis yang lebih baik. Meskipun tidak dapat dipungkiri memiliki kelebihan dan kekurangan (Coman \& Ronen, 2009) Adanya kelemahan dalam prakteknya karena analisis SWOT masih menggunakan pendekatan tradisional seperti pendekatan kualitatif, yang mana data yang diperoleh berupa narasi atau kata-kata yang masih mengandung unsur subjektif dari sumber data atau informan ((Phadermrod, Crowder, \& Wills, 2019)

Dari kelemahan ini, penulis mencoba menngunakan analisis SWOT dengan mengkombinasi data kualitaif dan kuantitatif, agar diperoleh informasi yang memiliki kreadible, valid, realible dan terukur pada masingmasing komponen yang dianalisis. Menurut Kurttila, M., et al. (dalam (Oreski, Oreski, \& Oreski, 2012). Analisis SWOT digunakan sebagai alat untuk menganalisis faktor internal dan eksternal dan dukungan keadaan suatu organisasi untuk mengatasi permasalahan yang menghambat tujuan organisasi. Tujuan akhir dari proses perencanaan strategis, di mana SWOT adalah salah satu tahap awal, adalah pengembangan dan adopsi strategi yang menghasilkan hubungan yang baik antara faktor internal dan eksternal. (Oreski et al., 2012) Analisis SWOT adalah alat penting yang berfungsi sebagai pendukung untuk pengambilan keputusan dan sering digunakan sebagai alat untuk analisis sistematis organisasi, baik pengaruh internal maupun eksternal pada organisasi (Yüksel \& Dağdeviren, 2007). Pada tahap mengidentifikasi kekuatan, kelemahan, peluang dan ancaman, organisasi dapat membangun strategi berdasarkan kekuatan, menghilangkan kelemahan dan mengeksploitasi kemampuannya, atau menggunakan. Pada analisis SWOT yang paling utama mementukan faktor strategis organisasi yang mempengaruhi masa depan organisasi itu sendiri (Yüksel \& Dağdeviren, 2007).

Salah satu keuntungan dari analisis SWOT adalah metode penilaian. dan evaluasi suatu pekerjaan. SWOT telah terbukti sangat berguna dalam memahami lingkungan organisasi terutama pada tahap perencanaan strategis (Jeon \& Kim, 2011). Saat menyusun analisis SWOT, penulis membuat tabel yang terdiri dari empat kolom untuk membuat daftar setiap elemen yang 
berdampak secara berdampingan untuk perbandingan. Kekuatan dan kelemahan biasanya tidak akan cocok dengan peluang dan ancaman, meskipun keduanya harus berkorelasi, karena pada akhirnya saling keterkaitan satu sama lain.

\section{METODE}

Agar memperoleh pemahaman yang mendalam sesuai dengan tujuan penelitian maka, metode peneltian yang digunakann yaitu; 1) Bila dilihat dari jenis penelitian yang digunakan adalah survey yaitu jenis penelitian yang menanyakan kepada beberapa responden melalui instrument (angket) tentang kepercayaannya, pendapatpendapat, karakteristik, dan perilaku yang telah atau sedang terjadi (Adiyanta, 2019); 2) dilihat dari metode yang digunakan adalah metode kuantitatif yaitu sebuah metode yang menjelaskan fenomena dengan mengumpulkan data numerik yang dianalisis dengan menggunakan statistik melalui langkah demi langkah. ((Muijs, Aubrey, Harris, \& Briggs, 2004)) dan; 3) Bila dilihat dari pendakatan dan analisis data yang digunakan, penelitian deskriptif yaitu penelitian yang menggambarkan dan memaparkan suatu kejadian, peristiwa, kondisi, kegiatan suatu wilayah (Sugiyono, 2010).

Berangkat dari pendekatan penelitian, maka, penelitian ini tidak ada generalisir dari populasi, jumah dosen sebagai sumber data sebanyak 26 orang dosen yang diambil secara sengaja untuk mewakili delapan program studi dan mereka dianggap memiliki pengetahuan lebih tentang permasalahan yang diteliti. Pengumpulan data dengan menggunakan angket tertutup dan terbuka dengan bantuan Google. Doc. Analisis data terdiri dari dua tahap yaitu; pada tahap pertama analisis deskriptif yaitu menggambarkan atau meringkas data dengan cara yang bermakna dan berguna disajikan dalam bentuk, grafik dan diagram, kemudian dihitung bobot dalam bentuk tabel kelas interval dan menarik kesimpulan. Tahap kedua analisis dengan menggunakan analisis SWOT yaitu, model analisis yang berfokus pada kekuatan, kelemahan, peluang dan ancaman atau dalam Bahasa inggrisTrengths, Weaknesses, Opportunities And Threats (SWOT).

\section{HASIL DAN PEMBAHASAN}

Berdasarkan hasil temuan mengenai kelayakan pembentukan lembaga penerbit (UMT Press) Universitas Muhammadiyah Tangerang, ditemukan beberapa faktor pendukung seperti pada aspek sumber daya manusia (SDM) yang mencakup; pengalaman mengajar dan menulis dan, beberapa kekuatan, kesempatan hambatan dan ancaman. Data hasil temuan dianalisis secara deskriptip terlebih dahulu sebelum ke tahap analis SWOT.

\section{Analisis Data Deskriptif}

Analisis data dekripsi bertujuan untuk melihat keadaan data jawaban dari responden yang mencakup; jumlah data, frekuensi observasi, frekuensi relative, frekuensi kumulatif yang disajikan dalam bentuk tabel dan grafik sebagai berikut:

\section{Pengalaman Mengajar Dosen}

Dari hasil sebaran instrumen diperoleh data pengalaman mengajar 26 orang dosen. Dengan rata-rata memiliki pengalaman mengajar > 10 tahun, bila kita merujuk pada pengaruh pengalaman terhadap kemampuan seserorang, kemungkinan akan memiliki pengaruh yang signifikan. Ini juga dapat dijadikan bahan untuk dipertimbangkan oleh lembaga penerbit UMT press, dan dapat dijadikan sebagai aspek kekuatan (strength) bagi lembaga. Namun aspek usia produktif perlu diperhitungkan juga. Artinya pengalaman mengajar tidak dapat dijadikan sebagai komponen kekuatan penuh. Mengenai keadaan data dapat dilihat pada tabel 1 sebagai berikut:

Tabel 1.

Data Pengalaman Dosen Mengajar

\begin{tabular}{|c|c|c|c|c|}
\hline $\begin{array}{c}\text { Lama } \\
\text { Mengajar (x) }\end{array}$ & Fo & X.Fo & $F_{\text {relatif } \%}$ & $F_{\text {kum }}$ \\
\hline 3 & 1 & 3 & 3.8 & 0 \\
\hline 4 & 4 & 16 & 15.4 & 19.2 \\
\hline 5 & 3 & 15 & 11.5 & 30.8 \\
\hline 6 & 2 & 12 & 7.7 & 38.5 \\
\hline 8 & 2 & 16 & 7.7 & 46.2 \\
\hline 10 & 3 & 30 & 11.5 & 57.7 \\
\hline 11 & 2 & 22 & 7.7 & 65.4 \\
\hline 12 & 1 & 12 & 3.8 & 69.2 \\
\hline 13.5 & 1 & 13.5 & 3.8 & 73.1 \\
\hline 15 & 3 & 45 & 11.5 & 84.6 \\
\hline 18 & 1 & 18 & 3.8 & 88.5 \\
\hline 23 & 1 & 23 & 3.8 & 92.3 \\
\hline 26 & 1 & 26 & 3.8 & 96.2 \\
\hline 34 & 1 & 34 & 3.8 & 100 \\
\hline Total & 26 & 285.5 & 100 & \\
\hline
\end{tabular}

Data Pengalaman Dosen Mengajar pada tabel 1 di atas dengan rata-rata Xfo $/$ fo $=285.5 / 26=11.00$ tahun, median $11+12 / 2=11.50$, minimum $=3.00$ maximum $=34.00$. dengan data ini dapat dilihat bahwa rata-rata dosen mengajar 11 tahun dimana paling sedikit pengalaman 3 tahun dan yang paling lama 34 tahun. Untuk lebih jelas mengenai data pengalaman mengajar dosen dapat dilihat pada grafik berikut:

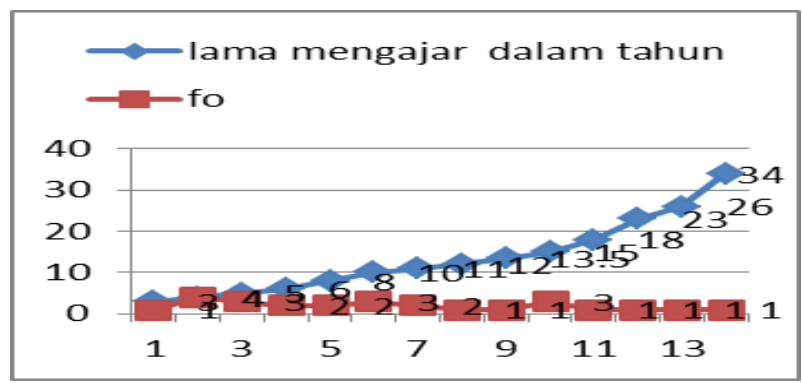

Gambar 1. Grafik Lama Mengajar Dosen 


\section{Pengalaman Menulis Buku}

Untuk menjaring data tentang pengalaman menulis buku, pada penelitian menggunakan pertanyaan tertutup "Apa Pernah Menulis Buku"? dengan dua pilihan jawaban secara dikotomi dengan nilai 1 dan 0. Dari hasil pertanyaan diperoleh jawaban dari para dosen sebagai data seperti pada tabel berikut:

\section{Tabel 2.}

Pengalaman Menulis buku

\begin{tabular}{|c|c|c|c|}
\hline Jawaban & Fo & Frel & Fkum \\
\hline Mungkin & 4 & 15.4 & 15.4 \\
\hline Tidak pernah & 9 & 34.6 & 50.0 \\
\hline Pernah menulis & 13 & 50.0 & 100.0 \\
\hline Total & $\mathbf{2 6}$ & $\mathbf{1 0 0 . 0}$ & \\
\hline
\end{tabular}

Data mengenai pengalaman menulis dosen pada tabel 2 di atas diperoleh tiga jawaban dari dosen yaitu; yang menjawab mungkin penulis memberi skor berupa - 1 (merujuk pada teori probabilitas). Jadi jumlah responden yang menjawab mungkin sebanyak 4 orang $15 \%$ dari 26 orang dosen, yang menjawab tidak pernah menulis buku (skor 0) sebanyak 9 orang atau $34.6 \%$ dari 26 orang dosen dan, yang menjawab pernah menulis buku (skor 1) sebanyak 13 orang atau $50 \%$ dari 26 orang dosen. Jadi secara secara deskriptif dapat disimpulkan; dosen yang pernah menulis buku lebih tinggi dari yang tidak pernah menulis buku di lingkungan Universitas Muhammadiyah Tangerang. Untuk lebih jelas mengenai data pengalaman menulis dosen dapat dilihat pada grafik berikut:

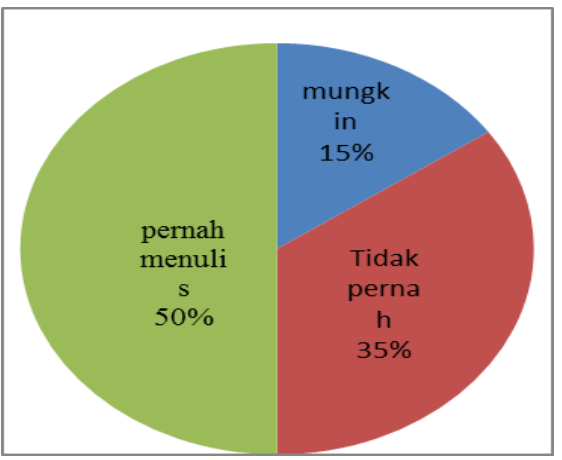

\section{Gambar 2. Grafik Pengalaman Menulis buku}

\section{Mengikuti Pelatihan Menulis}

Untuk menjaring data tentang dosen pernah atau tidak mengikuti pelatihan menulis buku, pada penelitian menggunakan pertanyaan tertutup "Apa Pernah mengikuti Menulis Buku"? dua pilihan jawaban secara dikotomi dengan nilai 1 dan 0 . Dari hasil pertanyaan diperoleh jawaban dari para dosen sebagai data seperti pada tabel berikut:

Tabel 3.

Pelatihan Menulis Buku

\begin{tabular}{|l|c|c|c|}
\hline \multicolumn{1}{|c|}{ Jawaban } & Fo & Frel & Fkum \\
\hline Tidak pernah & 13 & 50.0 & 50.0 \\
\hline Pernah menulis & 13 & 50.0 & 100.0 \\
\hline Total & $\mathbf{2 6}$ & $\mathbf{1 0 0 . 0}$ & \\
\hline
\end{tabular}

Data mengenai pengalaman menulis dosen pada tabel 3 di atas diperoleh dua jawaban dari dosen yaitu; jumlah responden yang menjawab tidak pernah mengikuti pelatihan menulis buku (skor 0) sebanyak 13 orang atau $50.0 \%$ dari 26 orang dosen dan, yang menjawab pernah mengikuti pelatihan menulis buku (skor 1) sebanyak 13 orang atau $50 \%$ dari 26 orang dosen. Jadi secara secara deskriptif dapat disimpulkan; dosen yang pernah mengikuti pelatihan menulis buku sama banyak dengan dosen yang tidak pernah mengikuti menulis buku di lingkungan Universitas Muhammadiyah Tangerang

\section{Ghost Writer/ Penulisan Bayangan}

Untuk menjaring data tentang dosen memerlukan penulisan bayangan / Ghost Writer dan yang tidak memerlukan penulisan bayangan / Ghost Writer, pada penelitian menggunakan pertanyaan tertutup "Apa memerlukan penulisan bayangan / Ghost Writer?" dengan dua pilihan jawaban secara dikotomi dengan nilai 1 dan 0 . Dari hasil pertanyaan diperoleh jawaban dari para dosen sebagai data seperti pada tabel berikut:

Tabel 4.

Ghost Writer / Penulisan Bayangan

\begin{tabular}{|l|c|c|c|}
\hline Jawaban & Fo & Frel & Fkum \\
\hline Tidak pelu & 19 & 73.1 & 73.1 \\
\hline Perlu & 7 & 26.9 & 100.0 \\
\hline Total & $\mathbf{2 6}$ & $\mathbf{1 0 0 . 0}$ & \\
\hline
\end{tabular}

Data mengenai dosen yang membutuhkan Ghost Writer / Penulisan Bayangan pada tabel 4 di atas diperoleh dua jawaban dari dosen yaitu; jumlah responden yang menjawab tidak perlu Ghost Writer / Penulisan (skor 0) sebanyak 19 orang atau $73.1 \%$ dari 26 orang dosen dan, yang menjawab pelu (skor 1) sebanyak 7 orang atau $26.9 \%$ dari 26 orang dosen. Jadi secara secara deskriptif dapat disimpulkan; dosen yang tidak memerlukan penulisan bayangan lebih tinggi dari yang memerlukan penulisan bayangan di lingkungan Universitas Muhammadiyah Tangerang.

\section{Memerlukan Marketing dan Distribusi}

Untuk menjaring data tentang dosen memerlukan Marketing dan Distribusi dan yang tidak memerlukan Marketing dan Distribusi, pada penelitian menggunakan pertanyaan tertutup "Apa memerlukan Marketing dan Distribusi?" dengan dua pilihan jawaban secara dikotomi dengan nilai 1 dan 0. Dari hasil pertanyaan diperoleh jawaban dari para dosen sebagai data seperti pada tabel berikut:

Tabel 5.

Marketing dan Distribusi

\begin{tabular}{|l|c|c|c|}
\hline Jawaban & Fo & Frel & Fkum \\
\hline Tidak pelu & 9 & 34.6 & 34.6 \\
\hline Perlu & 17 & 65.4 & 100.0 \\
\hline Total & $\mathbf{2 6}$ & $\mathbf{1 0 0 . 0}$ & \\
\hline
\end{tabular}

Data mengenai dosen yang membutuhkan Marketing dan Distribusi pada tabel 5 di atas diperoleh dua 
jawaban dari dosen yaitu; jumlah responden yang menjawab tidak perlu Marketing dan Distribusi (skor 0) sebanyak 9 orang atau $34.6 \%$ dari 26 orang dosen dan, yang menjawab pelu (skor 1) sebanyak 17 orang atau $65.4 \%$ dari 26 orang dosen. Jadi secara secara deskriptif dapat disimpulkan; dosen yang memerlukan marketing dan distribusi lebih tinggi dari yang tidak memerlukan marketing dan distribusi di lingkungan Universitas Muhammadiyah Tangerang

Jenis - Jenis Tulisan Dosen

Jumlah tulisan dosen 10 tahun terakhir berupa buku, jurnal, artikel maupun buku fiksi yang diterbitkan oleh berbagai lembaga penerbit dari tahun 2010 - 2020 seperti pada tabel berikut:

Tabel 6.

Jenis - Jenis Tulisan Dosen

\begin{tabular}{|c|c|c|c|}
\hline No & Jenis Tulisan Dosen & Fo & Frel (\%) \\
\hline 1 & Buku ajar & 56 & 32.7 \\
\hline 2 & Artikel & 47 & 27.4 \\
\hline 3 & Jurnal & 54 & 31.5 \\
\hline 4 & Cerpen & 6 & 3.5 \\
\hline 5 & Lain-lain & 8 & 4.6 \\
\hline & Jml & 171 & \\
\hline
\end{tabular}

Data mengenai tulisan dosen 10 tahan terakhir berupa buku ajar sebanyak 56 buku, 47 artikel, 54 jurnal, 6 cerpen, 8 lain-lain dengan jmlah secara keseluran sebanyak 171 tulisan dengan nilai rata-rata $171 / 5=34.2$. Jadi secara secara deskriptif dapat disimpulkan; dosen yang menulis buku ajar lebih banyak dari pada yang lain di lingkungan Universitas Muhammadiyah Tangerang. ntuk lebih jelas dapat dilihat pada grafik berikut:

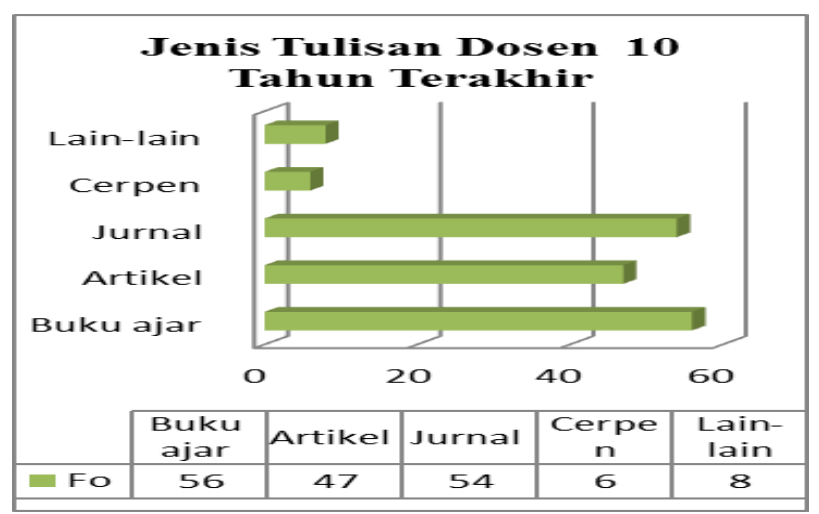

\section{Gambar 3. Grafik Tulisan Dosen}

\section{Jasa UMT Press}

Berdasarkan data yang dikumpulkan mengenai jumlah dosen yang tertarik menggunakan jasa UMT Press dapat dilihat pada tabel berikut:

Tabel 7.

Data Dosen yang Tertarik Menggunakan Jasa UMT Press

\begin{tabular}{|c|c|c|c|}
\hline No & Jenis Tulisan Dosen & Fo & Frel (\%) \\
\hline 1 & Tidak tertarik & 2 & 7.7 \\
\hline 2 & Tertarik & 24 & 92.3 \\
\hline & Jml & 26 & 100 \\
\hline
\end{tabular}

Data mengenai dosen yang tertarik menggunakan jasa UMT press yang tidak tertarik hanya 2 orang atau $7.7 \%$ dari 26 orang jumlah responden, sementara yang tertarik sebanyak 24 orang atau $92.3 \%$ dari jumlah responden. Jadi secara deskriptif dapat disimpulkan; dosen yang tertarik lebih tinggi dari yang tidak tertarik menggunakan jasa UMT Press di lingkungan Universitas Muhammadiyah Tangerang

\section{Alasan Dosen Menulis}

Dari jumlah 26 orang dosen yang menulis, 15 orang dosen yang beralasan karena tugas atau kewajiban atau $57.6 \%$ sisa 11 orang atau $42.3 \%$ menyatakan menulis bagian dari hobi.

Sebaran Lembaga Penerbit Sebagai Kompetitor

Jumlah lembaga penerbit yang pernah menerima atau yang mengelola hasil tulisan dosen di lingkungan UMT sebagai berikut:

Tabel 8.

Data Penerbit Sebagai Kompetitor

\begin{tabular}{|c|l|l|}
\hline No & Nama Penerbit & \multicolumn{1}{|c|}{ Alamat } \\
\hline 1 & Pustaka Getok Tular & $\begin{array}{l}\text { Taman } \\
\text { Graha Asri } \\
\text { Blok EE 3/2 } \\
\text { Kota Serang }\end{array}$ \\
\hline 2 & Gan Publishing & - \\
\hline 3 & Salemba Diniyah & Jakarta \\
\hline 4 & GAN Publishing & Jakarta \\
\hline 5 & Erlangga dan Gan Publising & Surabaya \\
\hline 6 & Graha Ilmu & $\begin{array}{l}\text { Pamulang } \\
\text { Tangerang } \\
\text { selatan }\end{array}$ \\
\hline 7 & Mitra Wacana Media & Bekasi \\
\hline
\end{tabular}

Kesulitan/ Hambatan

Hambatan-hamabtan yang dialamai oleh para dosen dalam menulis dari hasil pertanyaan penelitian diperoleh jawaban yang cukup beragam seperti pada tabel berikut:

Tabel 9.

Kesulitan/ Hambatan

\begin{tabular}{|c|c|c|}
\hline Hambatan & Fo & $\%$ \\
\hline $\begin{array}{l}\text { Belum mengetahui prosedur /cara } \\
\text { menulis }\end{array}$ & 3 & 11.53 \\
\hline Cetaknya mahal & 3 & 11.53 \\
\hline Ide dan gagasan & 1 & 3.84 \\
\hline Kurang fokus & 1 & 3.84 \\
\hline Kurangnya referensi dan mahal & 6 & 23.07 \\
\hline Menyediakan waktu & 10 & 38.46 \\
\hline penerbitan & 1 & 3.84 \\
\hline Saat ini fokus pada Disertasi & 1 & 3.84 \\
\hline jmlah & 26 & \\
\hline
\end{tabular}

Data mengenai kesulitan dan hambatan yang dialami oleh dosen dalam menulis hasil peneltian diperoleh dosen yang yang menjawab belum mengetahui prosedur /cara menulis sebanyak 3 orang 
atau $11.5 \%$ dari 26 orang dosen, yang menjawab cetaknya mahal sebanyak 3 orang atau $11.5 \%$ dari 26 orang dosen, yang menjawab kekurangan ide atau gagasan dan kurang fokus sebanyak 1 orang atau 3.8 $\%$ dari 26 orang dosen, yang menjawab kurang referensi dan mahal sebanyak 6 orang atau $23.0 \%$ dari 26 orang dosen, yang menjawab tidak cukup waktu atau sibuk denga kegiatan lain sebanyak 10 orang atau 38. $4 \%$ dari 26 orang dosen, yang menjawab kesulitan tempat untuk menerbitkan tulisan dan fokus penulisan disertasi masing-masing 1 orang atau $3.8 \%$ dari 26 orang dosen. Secara lebih jelas dapat dilihat dari grafik berikut:

\section{Gambar 4}

\section{Grafik Hambatan Dosen Dalam Menulis}

\begin{tabular}{|r|c|c|}
\hline Saat ini fokus... & 1 & \\
penerbitan & 1 & \\
Menydiakan waktu & & 10 \\
Kurangnya... & 6 & \\
Kurang fokus & 1 & \\
Ide dan gagasan & 1 & \\
Cetalnya mahal & 3 & \\
Belum... & 3 & \\
& & 20 \\
\hline
\end{tabular}

Bila diperhatikan pada grafik di atas yang menjadi hambatan dosen dalam menulis disebabkan oleh ketersediaan waktu menempati urutan teratas dan disusul kurang referensi dan mahal biaya cetak.

\section{Analisis SWOT}

Sebelum dilakukan analisis SWOT data frekuensi observasi (fo) pada aspek kekuatan (strength) dan kelemahan (weakness) data dibuatkan kelas interval untuk menenentukan level atau kategori data sebagai berikut:

$\begin{array}{ccccc}11 & 9 & 24 & 1 & 34 \\ 13 & 2 & 15 & 6 & 1 \\ 13 & 11 & 9 & 10 & \\ 19 & 3 & 13 & 1 & \\ 17 & 3 & 7 & 1 & \end{array}$

$$
\begin{array}{ll}
\text { Jangkauan } & =\max -\min =34-1=33 \\
\text { Banyak kelas } & =1+3.3(\log \mathrm{n} 22) \\
& =4.3(1.34)=5 \\
\text { Panjang kelas } & =\mathrm{j} / \mathrm{k}=33 / 5=6,6 \text { ditetapkan } 7
\end{array}
$$

Tabel 10.

Kategori Level Skor

\begin{tabular}{|c|c|c|c|c|}
\hline No & Strength & Skor & Bobot & $\begin{array}{l}\text { Total }= \\
\text { S x B }\end{array}$ \\
\hline 1 & $\begin{array}{l}\text { Rata-rata } \\
\text { Pengalaman dosen } \\
\text { mengajar } \\
\end{array}$ & 2 & 0.09 & 0.18 \\
\hline 2 & Pernah menulis & 2 & 0.09 & 0.18 \\
\hline 3 & $\begin{array}{l}\text { Pernah ikut } \\
\text { pelatihan menulis }\end{array}$ & 2 & 0.09 & 0.18 \\
\hline 4 & \begin{tabular}{|l|} 
Tidak pelu \\
penulisan bayangan
\end{tabular} & 2 & 0.09 & 0.18 \\
\hline 5 & $\begin{array}{l}\text { keinginan dosen } \\
\text { adanya marketing } \\
\text { professional }\end{array}$ & 3 & 0.14 & 0.41 \\
\hline 6 & $\begin{array}{l}\text { Rata2 jenis karya } \\
\text { tulis dosen selama } \\
10 \text { tahun terakhir }\end{array}$ & 5 & 0.23 & 1.14 \\
\hline 7 & $\begin{array}{l}\text { Ketertarikan dosen } \\
\text { terhadap adanya } \\
\text { UMT Press } \\
\end{array}$ & 4 & 0.18 & 0.73 \\
\hline 8 & $\begin{array}{l}\text { Dosen yang merasa } \\
\text { bahwa menulis } \\
\text { sebagai kewajiban }\end{array}$ & 2 & 0.09 & 0.18 \\
\hline & $\begin{array}{l}\text { jumlah total } \\
\text { Strength } \\
\end{array}$ & 22 & & 3.18 \\
\hline no & Weakness & Skor & Bobot & $\begin{array}{l}\text { Total }= \\
\text { S } \times B\end{array}$ \\
\hline 1 & $\begin{array}{l}\text { Tidak pernah } \\
\text { menulis } \\
\end{array}$ & 2 & 0.11 & 0.21 \\
\hline 2 & $\begin{array}{l}\text { Tidak pernah ikut } \\
\text { pelatihan } \\
\end{array}$ & 2 & 0.11 & 0.21 \\
\hline 3 & $\begin{array}{l}\text { Perlu ada bantuan } \\
\text { penulisan bayangan }\end{array}$ & 1 & 0.05 & 0.05 \\
\hline 4 & $\begin{array}{l}\text { Tidak memahami } \\
\text { marketing }\end{array}$ & 2 & 0.11 & 0.21 \\
\hline 5 & $\begin{array}{l}\text { Tidak tertarik } \\
\text { dengan UMT Press }\end{array}$ & 1 & 0.05 & 0.05 \\
\hline 6 & $\begin{array}{l}\text { Tidak Suka } \\
\text { Menulis }\end{array}$ & 2 & 0.11 & 0.21 \\
\hline 7 & $\begin{array}{l}\text { Belum mengetahui } \\
\text { prosedur /cara } \\
\text { menulis } \\
\end{array}$ & 1 & 0.05 & 0.05 \\
\hline 8 & Cetaknya mahal & 1 & 0.05 & 0.05 \\
\hline 9 & Ide dan gagasan & 1 & 0.05 & 0.05 \\
\hline 10 & Kurang focus & 1 & 0.05 & 0.05 \\
\hline 11 & $\begin{array}{l}\text { Kurangnya } \\
\text { referensi dan } \\
\text { mahal } \\
\end{array}$ & 1 & 0.05 & 0.05 \\
\hline 12 & \begin{tabular}{|l|}
$\begin{array}{l}\text { Menyediakan } \\
\text { waktu }\end{array}$ \\
\end{tabular} & 2 & 0.11 & 0.21 \\
\hline 13 & masalah penerbitan & 1 & 0.05 & 0.05 \\
\hline \multirow[t]{3}{*}{14} & $\begin{array}{l}\text { Saat ini fokus pada } \\
\text { Disertasi }\end{array}$ & 1 & 0.05 & 0.05 \\
\hline & jumlah weakness & 19 & & 1.53 \\
\hline & $\begin{array}{l}\text { Total Strength - } \\
\text { Total Weakness } \\
\end{array}$ & & & 1.66 \\
\hline
\end{tabular}

\begin{tabular}{|c|c|c|}
\hline Kelas interval & Level Skor & Kategori \\
\hline $1-8$ & 1 & Lemah \\
\hline $9-16$ & 2 & Kurang kuat \\
\hline $17-22$ & 3 & Cukup \\
\hline $23-28$ & 4 & Kuat \\
\hline $29-36$ & 5 & Sangat kuat \\
\hline
\end{tabular}

Tabel 11.

Total Strength - Total Weakness 
Dari perhitungan pada tabel $11 \mathrm{di}$ atas, diperoleh suatu gambaran bahwa lembaga penerbit UMT Press memiliki kekuatan sebesar 3,18, hal ini menandakan kekauatan masih dalam kategori cukup (lihat tabel 10 di atas) dan kelemahan sebesar 1,53 (lemah) jika kekuatan dipergunakan untuk menyingkirkan kelemahan (Total Strength - Total Weakness $=3,18-1,53=1.66$ (positif), hal ini menandakan, meskipn kekuatan yang dimiliki oleh lembaga penerbit UMT Press digunakan untuk menutupi kelemahannya, lembaga tersebut masih memiliki sisa kekuatan yang dapat diandalkan.

Untuk melihat aspek kesemapatan (Opportunities) dan ancaman bagi lemabaga UMT Press dapat dlihat dari perhitungan pada tabel 12 berikut:

Tabel 12.

Total Opportunities - Total Threats

\begin{tabular}{|c|c|c|c|c|}
\hline No & Opportunities & Skor & $\begin{array}{c}\text { Bob } \\
\text { ot }\end{array}$ & $\begin{array}{c}\text { Total }= \\
\text { S x B }\end{array}$ \\
\hline 1 & $\begin{array}{l}\text { Surat Keputusan } \\
\text { Rektor Universitas } \\
\text { Muhammadiyah } \\
\text { Tangerang No. } \\
\text { 038/KEP/III.3/D/202 } \\
\text { 0 tentang } \\
\text { pembentukan tim } \\
\text { perumus } \\
\text { pembentukan } \\
\text { Lembaga Penerbit } \\
\text { (UMT Press) } \\
\text { Universitas } \\
\text { Muhammadiyah } \\
\text { Tangerang pada } \\
\text { tanggal } 6 \text { Januari } \\
\text { 2020 }\end{array}$ & 4 & 0.07 & 0.29 \\
\hline \multirow[t]{9}{*}{2} & $\begin{array}{l}\text { Memiliki fakultas } \\
\text { dan program studi }\end{array}$ & & & \\
\hline & a. Paska Sarjana & 4 & 0.07 & 0.29 \\
\hline & b. FKIP & 4 & 0.07 & 0.29 \\
\hline & $\begin{array}{l}\text { c. Ilmu Pemerintahan } \\
\text { FISIP }\end{array}$ & 4 & 0.07 & 0.29 \\
\hline & $\begin{array}{l}\text { d. Fakultas Ekonomi } \\
\text { Bisnis }\end{array}$ & 4 & 0.07 & 0.29 \\
\hline & e. Fakultas Tekhnik & 4 & 0.07 & 0.29 \\
\hline & f. Parinkraf & 4 & 0.07 & 0.29 \\
\hline & $\begin{array}{l}\text { g. Profesi Ners/ } \\
\text { Fikes }\end{array}$ & 4 & 0.07 & 0.29 \\
\hline & h. Fakultas Hukum & 4 & 0.07 & 0.29 \\
\hline 3 & $\begin{array}{l}\text { UMT Press } \\
\text { menargetkan } \\
\text { minimal menerbitkan } \\
\text { setidaknya } 10 \text { buku/ } \\
\text { bulan atau } 100 \text { judul } \\
\text { buku dari dosen } \\
\text { penulis per tahun }\end{array}$ & 3 & 0.05 & 0.16 \\
\hline 4 & $\begin{array}{l}\text { UMT Press akan } \\
\text { bekerja sama dengan } \\
\text { APPTIMA/ APPTI }\end{array}$ & 3 & 0.05 & 0.16 \\
\hline
\end{tabular}

\begin{tabular}{|c|c|c|c|c|}
\hline 5 & $\begin{array}{l}\text { UMT Press akan } \\
\text { bekerja sama dengan } \\
\text { Komite Buku } \\
\text { Nasional untuk } \\
\text { mendapatkan } \\
\text { kesempatan agar } \\
\text { buku-buku produksi } \\
\text { UMT bisa diikutkan } \\
\text { dalam berbagai } \\
\text { pameran buku } \\
\text { Nasional dan } \\
\text { Internasional. }\end{array}$ & 3 & 0.05 & 0.16 \\
\hline 6 & $\begin{array}{l}\text { UMT Press Akan } \\
\text { bekerja sama dengan } \\
\text { Komite Buku } \\
\text { Nasional agar dosen } \\
\text { penulis mendapatkan } \\
\text { kesempatan pelatihan } \\
\text { Nasional maupun } \\
\text { Internasional, atau } \\
\text { kesempatan } \\
\text { memperoleh program } \\
\text { residensial dari KBN }\end{array}$ & 3 & 0.05 & 0.16 \\
\hline \multirow[t]{3}{*}{7} & $\begin{array}{l}\text { Target dan sasaran } \\
\text { berikut dari UMT } \\
\text { Press adalah } \\
\text { memberikan } \\
\text { pelatihan/ } \\
\text { menerbitkan buku } \\
\text { dari mahasiswa UMT }\end{array}$ & 4 & 0.07 & 0.29 \\
\hline & $\begin{array}{l}\text { UMT Press akan } \\
\text { bekerjasama dengan } \\
\text { Pusat Kurikulum dan } \\
\text { Perbukuan } \\
\text { Kementrian } \\
\text { Pendidikan Nasional } \\
\text { RI, untuk } \\
\text { mendapatkan materi } \\
\text { buku ajar di } \\
\text { Perguruan Tinggi } \\
\text { yang bisa } \\
\text { dikembangkan oleh } \\
\text { dosen penulis }\end{array}$ & 3 & 0.05 & 0.16 \\
\hline & $\begin{array}{ll}\text { Jumlah } & \text { total } \\
\text { Opportunities }\end{array}$ & 55 & & 3.73 \\
\hline No & Threats & & & \\
\hline 1 & E-Book & 3 & 0.43 & 1.29 \\
\hline 2 & Internet (google) & 3 & 0.43 & 1.29 \\
\hline \multirow[t]{3}{*}{3} & $\begin{array}{l}\text { penerbit yang pernah } \\
\text { dipakai selama ini dll }\end{array}$ & 1 & 0.14 & 0.14 \\
\hline & $\begin{array}{ll}\text { Jumlah } & \text { total } \\
\text { Threats }\end{array}$ & 7 & & 2.71 \\
\hline & $\begin{array}{l}\text { Total Opportunities } \\
\text { - Total Threats }\end{array}$ & & & 1.01 \\
\hline
\end{tabular}

Dari perhitungan pada tabel 12 di atas, diperoleh suatu gambaran bahwa lembaga penerbit UMT Press memiliki kesempatan (Opportunities) sebesar 3,73 hal ini menandakan kesemptan masih dalam kategori cukup (lihat tabel 10 di atas) dan ancaman sebesar 2,71. 
